Chapman University

Chapman University Digital Commons

6-1-2015

Evaluating a Collaborative iPad Game's Impact on Social Relationships for Children with Autism Spectrum Disorder

LouAnne E. Boyd

Kathryn E. Ringland

Oliver L. Haimson

Helen Fernandez

Maria Bistarkey

See next page for additional authors

Follow this and additional works at: https://digitalcommons.chapman.edu/engineering_articles

Part of the Other Engineering Commons, Other Psychology Commons, Personality and Social Contexts Commons, and the Social Psychology Commons 


\section{Evaluating a Collaborative iPad Game's Impact on Social Relationships for Children with Autism Spectrum Disorder}

\section{Comments}

This is a pre-copy-editing, author-produced PDF of an article accepted for publication in ACM

Transactions on Accessible Computing, volume 7, issue 1, in 2015 following peer review. The definitive publisher-authenticated version is available online at https://doi.org/10.1145/2751564.

\section{Copyright}

Association for Computing Machinery

\section{Authors}

LouAnne E. Boyd, Kathryn E. Ringland, Oliver L. Haimson, Helen Fernandez, Maria Bistarkey, and Gillian R. Hayes 


\title{
Evaluating a Collaborative iPad Game's Impact on Social Relationships for Children with Autism Spectrum Disorder
}

\author{
LOUANNE E. BOYD, University of California, Irvine \\ KATHRYN E. RINGLAND, University of California, Irvine \\ OLIVER L. HAIMSON, University of California, Irvine \\ HELEN FERNANDEZ, La Habra City Schools \\ MARIA BISTARKEY, La Habra City Schools \\ GILLIAN R. HAYES, University of California, Irvine
}

\begin{abstract}
This paper describes how collaborative assistive technologies, housed on off-the-shelf low cost platforms such as the iPad, can be used to facilitate social relationships in children with autism spectrum disorder (ASD). Through an empirical study of the use of a collaborative iPad game, Zody, we explore how assistive technologies can be used to support social relationships, even without intervention from adults. We discuss how specific design choices can encourage three levels of social relationship: membership, partnership, and friendship. This work contributes to research on both assistive technologies and collaborative gaming through a framework that describes how specific in-game elements can foster social skill development for children with ASD.
\end{abstract}

Categories and Subject Descriptors: H5.2 [Information interfaces and presentation (e.g. HCI)]: User Interfaces---Evaluation/methodology, interaction styles; Group and Organization interfaces---Collaborative computing, Computer-support-cooperative work, Synchronous interaction, Theory and methods, K.4.2 [[Social Issues]: Assistive technologies for persons with disabilities

General Terms: Design, Human Factors

Additional Key Words and Phrases: collaborative games, iPad, autism, ASD, social skills, cooperation, social

\section{ACM Reference Format:}

Boyd, L. E., Ringland, K. E., Haimson, O. L., Fernandez, H., Bistarkey, M., and Hayes, G. R. 2014. ACM Trans. Access Comput. 2015. Evaluating a collaborative iPad game's impact on social relationships for children with autism spectrum disorder.

\section{INTRODUCTION AND BACKGROUND}

Individuals with Autism Spectrum Disorder (ASD) ${ }^{1}$ often experience difficulties developing social relationships [Baron-Cohen 1988, Dawson et al. 2004, Kasari et al.

Author's addresses: LouAnne E. Boyd, Department of Informatics, University of California, Irvine, CA 92697-3440; email: boydl@uci.edu; Kathryn E. Ringland, Department of Informatics, University of California, Irvine; Oliver L. Haimson, Department of Informatics, University of California, Irvine; Gillian R. Hayes, Department of Informatics, University of California, Irvine, Helen Fernandez and Maria Bistarky, La Habra City School District.

Permission to make digital or hardcopies of part or all of this work for personal or classroom use is granted without fee provided that copies are not made or distributed for profit or commercial advantage and that copies show this notice on the first page or initial screen of a display along with the full citation. Copyrights for components of this work owned by others than ACM must be honored. Abstracting with credits permitted. To copy otherwise, to republish, to post on servers, to redistribute to lists, or to use any component of this work in other works requires prior specific permission and/or a fee. Permissions may be requested from Publications Dept., ACM, Inc., 2 Penn Plaza, Suite 701, New York, NY 10121-0701 USA, fax +1 (212) 869-0481, or permissions@acm.org.

(C) 2010 ACM 1539-9087/2010/03-ART39 $\$ 15.00$

DOI:http://dx.doi.org/10.1145/0000000.0000000

${ }^{1}$ Autism Spectrum DisorderDisorders is an umbrella term used in the Diagnostic and Statistical Manual $5^{\text {th }}$ edition to describe a range of difficulties with social communication and repetitive behavior. In previous editions of the DSM, symptoms were clustered into categories such as autism, Asperger's syndrome, and Pervasive Developmental Disorder Not Otherwise Specified. 
2001, Travis and Sigman 1998], leading to social isolation [Ghaziuddin et al. 2002, White et al. 2007, Hurtig et al. 2009, Boyd and Ward 2013]. Rates of depression are substantially higher (25\% vs. $10 \%$ ) for people with ASD compared to the general population, potentially due to a lack of friends [Leyfer et al. 2006, Lieb 2011]. Of adults with ASD, only 8\% report interacting with a "friend" on a weekly basis [Orsmond et al. 2004]. Social difficulties can be improved through intervention across the lifespan [Gerhardt and Mayville 2010, Krasny et al. 2003, Reichow and Volkmar 2010]. To simplify thinking about social relationships and interventions to support them, we developed a framework of social relationships. Informed by our analysis of collaborative patterns among children with ASD when playing an iPad game, our framework includes three categories of social relationships with increasing levels of intimacy: membership, partnership, and friendship.

We define membership as being part of a group and participating, such as being physically present and making a small action that contributes to the group's activity. For example, membership can include sitting with a group at a table and saying 'hello' to the others already seated. Interventions that aim to address membership usually do so by focusing the training on a group of peers of which the child is expected to already be a part (e.g, Circe of Friends [Kalyva and Avramidis, 2005], peer-mediated social skills training [Laushey and Heflin 2000]).

Partnership, defined simply here as two people having specific responsibilities in achieving their mutual endeavor, has likewise been supported through a variety of interventions. For example, parent-assisted friendship training [Frankel et al. 2010] aims at teaching social etiquette and social rules to the child with ASD that are used by the child's peer group. Relationship Development Intervention (RDI) [Gutstein 2002] supports adults in teaching the collaborative interactions of partnership by systematically teaching synchronization and reciprocal responding as well as the highly emotional interactions of friendship. In this case, friendship consists of having mutual interests and an affinity for each other. Interventions designed to support friendships tend to include creating enriched emotional experiences that can become shared memories.

Across all of these types of social relationships, one substantial challenge remains. Interventions that support them currently require intensive effort from parents, therapists, and other mediators. Thus, in this work, we were interested in understanding whether and how technology might be used to support the building of social skills at all three of these levels with limited or no human mediation. To address this research question, we evaluated the use of a collaborative tablet game intended to teach social skills to children with ASD. Our results indicate that such games can be designed to support teaching social skills at all three levels of intimacy without a human mediator. However, the specific mechanisms by which such instruction occurs must be adapted to the particular skills, strengths, and challenges of the individuals using the game.

The remainder of this paper is structured as follows. First, we provide an overview of related work in interactive and collaborative technologies to support social skills development as well as gaming for socialization. We then detail our methods for this empirical study. Finally, we present the results of our study in light of these three levels of intimacy: membership, partnership, and friendship; closing with a discussion of how future technologies might be designed to support these skills. 


\section{RELATED WORK}

Research on using assistive technology to support social skills traditionally focuses on an individual user engaging with a device to support the development of specific skills [McCoy and Waller 2009]. For example, Tartaro and Cassell [2011] demonstrated that a life-sized virtual peer could be used to teach social skills by interacting with a child with ASD, sharing toys and responding to the child's input. Similarly, robots have been shown to be able to assist children with ASD in collaborative play that required continual communication, coordination and synchronization between the two participants [Wainer 2012]. Additionally, collaborative virtual environments [Cheng and Ye 2010], consisting of a 3D expressive avatar, an animated social situation, and verbal and text communication, allowed children with ASD to improve their social interactions and understanding of social interactions. Finally, in the ECHOS project, a technology that detects the user's eye gaze at objects on the screen and responds to the user based on where he is looking on the screen facilitated joint attention (the shared focus of two people) between the computer agent and the child with ASD [Porayska-Pomsta et al. 2012]. These projects demonstrate that technologies can be used to engage directly with children individually to teach specific social skills.

Building on this work, a growing body of research addresses social relationship skills by developing tools for multiple children with social skills deficits to collaborate using the same device [e.g., Gal et al. 2009, Hourcade et al. 2012, Piper et al. 2006]. Touchscreens and other shared interactive surfaces "allow face-to-face interaction and multiple simultaneous inputs from individuals acting independently or as part of a group" [Morris et al. 2006 as cited in Kientz et al. 2013], making them particularly compelling as platforms for developing collaborative applications and games for children with ASD. Because of their inherently collaborative features, touchscreens have been used in research studies to teach a variety of social skills.

In particular, the high levels of structure that can be imparted using touchscreens have been shown to improve student performance in joint activities [Bullock-Rest and Hansen 2007, Gal and Goren-Bar 2007, Hourcade et al., 2012]. For example, Piper et al. (2006) developed and evaluated a tabletop system to support the teaching of turn taking, called SIDES. By using a system that contained prescribed and limited choices, clear visual directions, and consistent feedback, SIDES not only encouraged turn taking during the game but improved social skills overall for participants. Likewise, as part of the Serious Games for PDD-NOS ${ }^{2}$ project, researchers found that by playing a collaborative game for approximately 20 minutes per day, students improved in their abilities to collaborate within the game. However, these skills did not generalize to other classroom skills [van Veen et al. 2009]. Although these projects are promising, they all use very large touchscreens, which are not cost effective for most schools and clinics and are too bulky for use in many situations.

With the advent of tablets and other mobile shared surfaces, smaller scale collaborative systems are much more likely to be used outside of the research setting. For instance, the Open Autism Project focused on the use of multi-touch tablets for encouraging social interactions "through creative, expressive, and collaborative activities" [Hourcade et al. 2013]. Hiniker et al. (2013) found that using game

${ }^{2}$ PDD-NOS stands for "Pervasive Developmental Disorder-Not Otherwise Specified", and was a diagnostic category used when social, communication and cognitive deficits that did not meet full criteria for autism while also not meeting criteria for another developmental disorder per the DSM-IV IV [APA 2000] 
elements in a suite of cognitive tasks on the tablet could support extended engagement in therapeutic activities.

Outside of the specific ASD technology community, multiplayer games have been shown to encourage sociability and communication among players [Seay et al. 2003] to accomplish shared goals [Brown and Gutwin 2003, Wendel et al. 2013]. Despite the concern that some video games may promote violence or other "anti-social" behaviors [The Harris Poll 2013], recent empirical research indicates that the rate of violence has actually decreased at the same time that sales of violent games have increased [Cunningham et al. 2011]. Even players of first person shooter games have been found to seek out social relationships with other players [Xu et al. 2011]. Collaborative virtual environments, including games, successfully encourage partnership by requiring users to use offline skills to carry out activities within a virtual environment [Bowers et al. 1996]. In fact, much of the "fun" of games may actually come from the relationships among players as they navigate game activities [Hughes et al. 1983, Nardi and Harris 2006].

The related research in ASD technologies demonstrates the feasibility of games and other collaborative technological systems to teach a variety of skills, including social skills, to individuals with ASD. At the same time, the more general field of collaborative gaming indicates that games are-perhaps unsurprisingly-inherently motivating and social in many cases. Playing with others can both provide some of the motivation needed to engage in a therapy and increase social interactions [McGrenere 1996]. Thus, in this work, we were interested in unpacking the relationship between specific game elements and levels of intimacy in social relationships for children with social skill challenges.

\section{METHODS}

To understand how a tablet based collaborative game might support the development of social skills, we conducted a quasi-controlled study in a school using a singlesubject design using an iPad game, Zody, and Lego play sets. Playing Legos together is a current best practice to support collaborative play in the school that served as the site for this study. Naturalistic approaches are considered most likely to produce generalization of such social skills [Delprato 2001, Krasny, 2003]. A natural, motivating real-life activity, such as Lego therapy [LeGoff, 2004 \& 2006], can produce improvement in indirect measures of autism-specific social interaction scores when compared to a direct teaching approach guided by a therapist [Owen 2008]. We conducted a within subjects $\mathrm{ABAB}$ study to observe how technology might augment social skill development when alternated with current practice. In this section, we provide details about the participants, the study design, and the Zody game used in the study.

\subsection{Participants}

Four dyads (eight children, including one female) aged 8 to $11(M=9.6 ; S D=0.7)$ participated in the study. Participants were recruited from a twelve-person special day class for students with ASD in the third through fifth grades (US). Nine students expressed interest in the study, and eight were randomly selected from among those nine to ensure even numbers. The students were taught to use Zody, before beginning the study. All participants had educational and parent-reported medical diagnoses of ASD. Each student was a member of a self-contained special education classroom at an elementary school district in Southern California (see Table 1). 


\begin{tabular}{llllll} 
Dyad & $\begin{array}{l}\text { Participant } \\
\text { Pseudonym }\end{array}$ & Age & Gender & Ethnicity & IQ (Standard Score)* \\
\hline A & Juan & 9 & Male & Hispanic & 113 \\
A & Tasha & 9 & Female & Hispanic & 87 \\
B & Anthony & 8 & Male & Caucasian & 98 \\
B & Robert & 10 & Male & Caucasian & 91 \\
C & Jesus & 10 & Male & Caucasian & 95 \\
C & Ignacio & 10 & Male & Hispanic & 72 \\
D & Andrew & 11 & Male & Asian/Hispanic & 93 \\
D & Max & 10 & Male & Hispanic & 89 \\
\hline
\end{tabular}

* IQ scores were derived from various cognitive assessments: Woodcock-Johnson Cognitive Assessment, Wechsler Intelligence Scale for Children (WISC-IV), Universal Nonverbal Intelligence test (UNIT), etc. The most current school records indicated IQ scores ranging from 72-113 (with 90110 being average intelligence).

\section{Table 1: Participant demographics.}

The Autism Social Skills Profile (ASSP) [Bellini and Hopf 2007] was completed by their parents and indicated they had moderate social skill deficits consistent with a diagnosis of ASD. Two of the three concerns noted most frequently in this instrument were engaged in the study design: considering multiple viewpoints and compromising during disagreements. The third major concern, introducing self to others, was not explored, because all of the students already knew each other through the class from which they were recruited. Participants were randomly assigned to dyads and remained with that partner for all study sessions.

\subsection{Study Design}

The study included an ABAB design [Kazdin 2011], to maximize the impact of the results across the eight participants [Sears and Hanson 2012]. The dyads played three times a week with a 401-piece Lego set in weeks one and three, and Zody during weeks two and four. Each dyad shared one iPad or one Lego set, enforcing some measure of engagement with one another. Three researchers observed each session, taking detailed notes about participant behaviors. The observations conducted during the intervention informed questions asked during short interviews conducted with each participant at the end of the study. Interviews were structured to collect maximal data in five to twenty minutes, which was all the time available given the constraints of conducting this research in a school setting. Additionally, the student participants often struggled to concentrate and maintain the social interaction necessary for an interview for longer than 20 minutes. Two researchers conducted each interview with one student at a time. All interviews were audiorecorded and transcribed for detailed analysis alongside observational data.

\subsection{Zody: A Collaborative Game for Teaching Social Skills}




\begin{tabular}{ll} 
DIR Social Engagement Strategies & Zody Features \\
\hline Develop joint attention & Tutorials \\
& Visual feedback \\
& Parallel game controllers \\
& Play starts automatically \\
& Tablet form \\
& Multiple mini-games \\
\hline Facilitate experience of mutual joy & Mutual goals \\
& Visual feedback \\
& Rewards for success \\
\hline Mirror affect & Visual feedback \\
& Sound effects \\
\hline Exaggerate your expression & Visual feedback (highlights affect) \\
\hline Turn action into interaction & Cooperative gestures \\
\hline Promote child's agenda & Rewards for success \\
\hline Be necessary means to an end & Cooperative gestures \\
\hline Use anticipation to increase mutual attention & Mystery game after gopher defeat \\
\hline
\end{tabular}

Table 2: Features of DIR therapy aligned with Zody component.

Zody, short for Zody's World: The Clock Catastrophe ${ }^{3}$, is a commercially available collaborative iPad game designed by SymPlay. The SymPlay website states that "each game includes a cooperative mode and helps you show how it's good to work together with other people and pay attention to what they're doing." ${ }^{4}$ The game includes four mini-games connected to a primary home scenario. Players return to the home scenario between the mini-games. The overall goal of the game is to collect several pieces to assemble a clock that has been stolen at the beginning of the game. In interviews with the game's designers, they indicated that the game was inspired by the DIR "Floor Time" model [Davis et al. 2014] (see Table 2).

In the home scenario, which is also another mini-game, one player's character carries the other player's character piggyback, avoiding hazards and incoming fruit
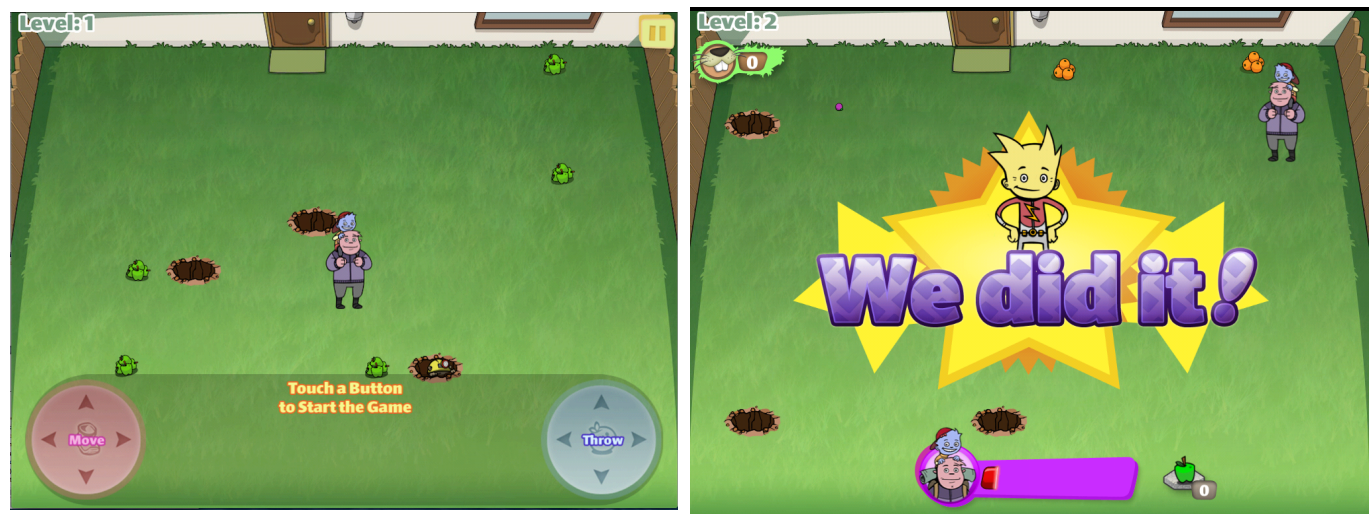

Figure 1: (left): The dual controls at the bottom of the screen allows one player to move while the other throws fruit at the gophers. (right): Screen text encourages celebration when "leveling up".

${ }^{3}$ Zody was developed by SymPlay at http://www.SymPlay.com

${ }^{4}$ Zody is retrievable at https://itunes.apple.com/us/app/zodys-world-clock-catastrophe/id821791253?mt=8 


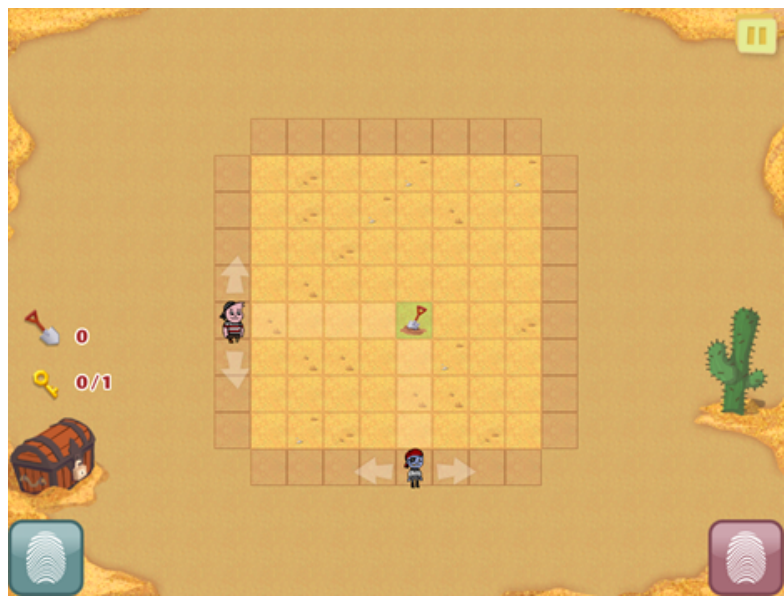

Figure 2: Players choose where to dig for treasure by first communicating about their choices, then each picking their respective coordinate (vertical or horizontal) and simultaneously placing their thumbs on the color-coded fingerprint icons to initiate digging.

thrown by gophers while that second character throws fruit at the gophers (See Figure 1).

The goal of the Treasure Chase mini-game is to dig for buried treasure in pairs by simultaneously pressing fingerprints to engage the digging action (see Figure 2). In the Dragon Blast mini-game, players each use an individual paddle to throw ice balls and break down the walls protecting a dragon that is in turn shooting fireballs at them. This mini-game provides each player their own side to play in a parallel fashion, and one side can help the other side by returning their partner's ice ball if it passes through the center of the screen (see Figure 3).

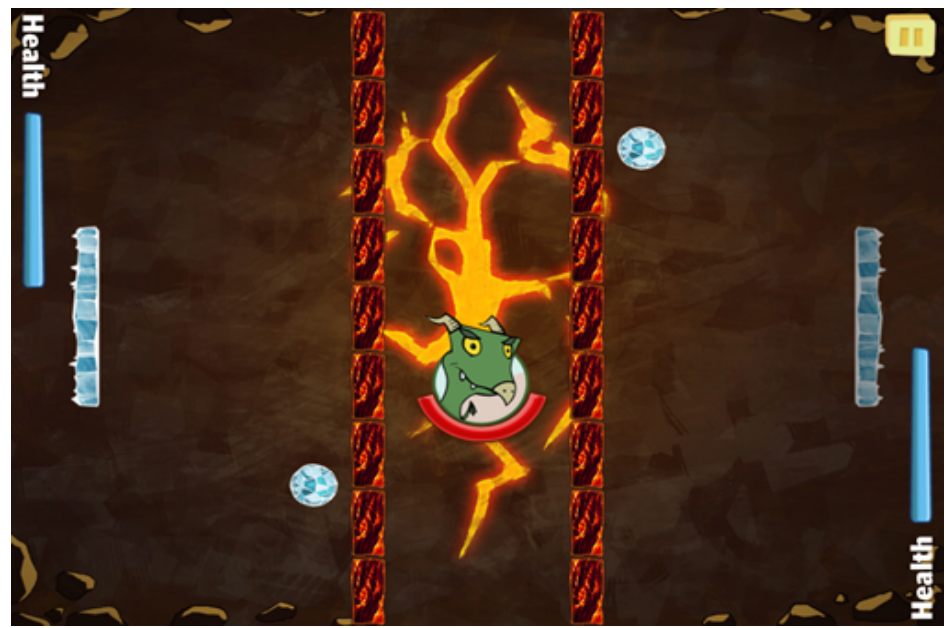

Figure 3: Each player has a controller from which they can throw ice balls at the dragon. 


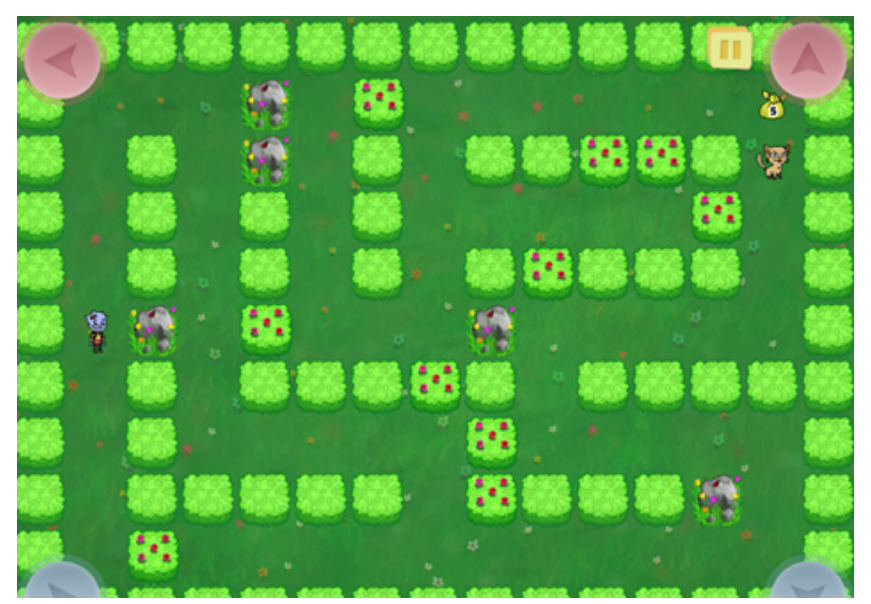

Figure 4: The color-coded arrows show the feature that requires cooperative gestures. The color-coding is designed to encourage each player to collaborate by controlling two of the four directions.

The Garden Maze has two modes: Tilt Maze and Arrow Maze. In Tilt Maze, players each hold a side of the iPad and turn synchronously to move their character through the maze. In Arrow Maze, each player controls two buttons, which each correspond to one direction (i.e., up, down, left, right) (see Figure 4).

Finally, in the Talk it Over mini-game, the players decide which characters (i.e., the strong, gentle character or the small, assertive character) will try a particular strategy (i.e., action, reasoning, empathy) to persuade the dragon to allow the characters to remove a painful thorn from the dragon's foot.

\subsection{Analysis}

Throughout data collection and analysis, the research team met regularly to discuss trends in the data collected from observations. Dominant topics included any usability or technical challenges the children were having as well as of social behaviors participants exhibited when using specific features of the game. All members of the research team read the interview transcripts from all participants.

Our overall analysis was a mix of inductive and deductive approaches. We examined the interview transcripts and field notes for data related to our initial hypotheses surrounding the potential feasibility of collaborative computer games to support a variety of social relationships and teach multiple social skills to students with ASD. Additionally, we looked for explanatory interview data to help understand the trends we saw in direct observations. We use "cooperative gestures" [Morris et al. 2006] as a means for explaining the ways in which the Zody game executes actions by multiple users. Specifically, Morris et al. (2006) describe six design axes that make up cooperative gestures:

- Symmetry: similarity in actions

- Parallelism: the temporal pattern of the interaction (simultaneous or serial)

- Proxemics distance: the physical distance of users during the interaction

- Additivity: the amplification of effect when more than one user makes a given gesture simultaneously

- Identity-Awareness: focus that comes from designated roles

- Number of Users and Number of Devices: complexity in learning and executing the actions 
Building on the concept of roles and collaborative actions and aligning with the tenants of Cognitive Behavioral Therapy, Giusti et al. (2011) developed a set of collaborative patterns ("choosing together", "constraints on object", "different role", and "ownership"). Taken together, these works describe the spectrum of involvement required or elicited from each player within a set of patterns and provide a framework by which we analyze interactions with Zody.

Our inductive analysis process included coding, memoing, and affinity diagramming throughout the data collection and analysis process [Charmaz and Belgrave 2002]. During the first round of open coding, codes focused on orientation and reactions to the game, as well as the concepts of negotiating play, friendship and partnership, and goal completion.

The first author drafted multiple memos describing her analysis of the interview data to serve as the basis for discussion with the rest of the research team. Additional rounds of coding and analysis examined the connection between specific game features and particular social skills, with an emphasis on known social skills lists from the ASD literature [Krasny 2003 et al. 2006, Wilcynzki et al. 2007]. Finally, to simplify understanding of the highly varied and complex social relationships observed, a set of memos were drafted using the framework of three levels of intimacy in the observed social relationships: membership, partnership, and friendship. Using these memos as the basis for discussion, we examined how the collaborative patterns differed between the two conditions. In particular, a framework of cooperative gestures [Morris et al. 2006, Giusti et al. 2011] game elements present in Zody impacted social skills during experimental sessions. We reduced the codes into categories of membership, partnership, and friendship by collapsing axial codes. We developed our framework using these categories by comparing behavior observed across both conditions. What we present here then are empirical results in light of the connection between features of collaborative play and the learning and practicing of social skills specifically in terms of membership, partnership, and friendship.

\section{RESULTS}

Our results indicate that cooperative assistive technologies, including video games, can support developing social skills at varying levels of intimacy between players. In particular, specific game features can support membership, partnership, and friendship without a human mediator. As described in the introduction, membership behaviors include physical proximity to other players and initiating participation through an interaction with the game. Partnership behaviors are collaboration through turn-taking and coordinating simultaneous actions. Friendship behaviors are sharing joy and demonstrating empathy.

In this section, we describe the ways in which the pairs in our study played together, with particular attention paid to the ways in which both traditional (Lego) and digital (Zody) supports facilitated these social relationships, noting features appropriate for the design and development of social games for children with ASD.

\subsection{Membership}

As noted in the introduction, membership can be defined as being part of a group and participating, such as being physically present and making a small action toward participation in the group's activity. Importantly, membership potentially results in the inclusion of people who are often socially isolated and have difficulty interacting 
with others. Membership behaviors signify that a person is part of the group. In our study, membership was supported in the Zody condition by the use of a small form factor, a somewhat unexpected benefit of the iPad platform, and by the assignment of roles. In the Lego condition, membership was supported by the use of one, relatively small booklet with instructions. The dyads all spontaneously organized themselves into one child reading the instructions and directing the other.

\subsubsection{Maintaining Physical Proximity through Small Form Factor}

Zody uses "social" cooperative gestures [Morris et al. 2006], meaning that participants touch the same device but not the same button within the game. The small size of an iPad requires students playing it together to sit or stand in close physical proximity to one another, which is in and of itself a goal of social skills therapy for many students. Specifically, close proximity can "encourage chance encounters and opportunities for interaction, which can lead to the formation of new relationships and the maintenance of existing ones" [Rivera et al. 2010]. Given that maintaining proximity tends to be listed by social skills experts as an explicit goal that students may not achieve naturally, it is perhaps unsurprising that the students in our study did not particularly like the size of the form factor used. For example, Robert ${ }^{5}$ conveyed his discomfort related to sharing the small space:

"The only problem is that sometimes it would get very crowded... The thing that would have made it better was if there was a full table for the iPad, like a full giant table, that like we can move. That would be easier for Zody...I mean, make it, make the iPad a bit bigger, the size of a table...It would make it a less frustrating for example if you have an iPad, a regular iPad and you have to share it with another guy. It's really hard because, you know, it isn't full roam. And, a table, a giant table, it would that would look like an iPad and would actually work... So it would make it less frustrating to control sometimes."

The very discomfort expressed is an indication that the form factor may help students to overcome their challenges with maintaining close proximity to others.

In turn, this close proximity can then lend itself to opportunities for other prosocial behaviors [Rivera et al. 2010]. In particular, once engaged in a shared physical space, students in this study became jointly engaged, leading them to describe themselves and act as members of a team or pair. For example, Juan stated that he and his partner "joined forces to get the dragon." and that he and Tasha "just played together. We played. And we just played together."

Our results indicate that the specific form factor chosen can help students to develop particular social skills. Given that children use physical proximity as a strategy to enter a social group [Bakeman and Brownlee 1980], the use of a small form factor to require increasing tolerance for sitting in close proximity with a peer can support learning these membership strategies. Of course, something larger (e.g., a tabletop) or more distant (e.g., online interactions) might be more appropriate for teaching other types of skills or for children for whom close physical proximity goes beyond simply challenging to extremely anxiety producing or even painful. Additionally, requiring extended coordination in such close proximity could cause

\footnotetext{
${ }^{5}$ Participants are referred to by pseudonyms.
} 
frustration. Those designing social skills interventions must understand the ways in which a digital intervention's physical form factor can impact the acceptance of the technology and possibly serve as an intervention itself.

\subsubsection{Participation through assigned roles}

Membership can also be facilitated by providing players with designated roles during gameplay. For example, Piper et al. (2006) prescribed identifiable roles for the players of a tabletop game and found that participants' roles influenced how the children played the tabletop game, with students performing particularly well when therapists assigned them the role of leader. In our study, participants negotiated these roles dynamically in both conditions. When initiating play, one or both would reach for the manual or the iPad. Notably, once a partner took a passive role in Lego play by being the builder for their partner instruction reader, it did not change within that session; whereas in Zody, roles changed throughout the play session as described below.

In Zody, roles were designated by the device (e.g., one player was the thrower and the other controlled character movement) or by the students themselves (e.g., one player clicked the character and strategy buttons in the Talk it Over mini-game), with no therapist intervention. The roles in each mini-game tend to be similar, if not equal, in terms of the impact on meeting the goal. For example, in the Garden Maze game, color-coding indicates that each participant has control of two directions, and all four are needed to navigate. In the Treasure Chase game, the two digger roles are equivalent in that each player can move in one of two directions and press one of two fingerprints. The Dragon Blast game allows players to blast the dragon from separate directions. The Gopher game has the most dissimilar roles in that one player is the "runner" and one the "thrower." Most players accepted the role of the character whose inputs were physically closest.

Although all of the games involve two players on screen, it is physically possible for a single player to play both roles. Thus, there were occasions when a participant attempted to take exclusive control of the iPad. For example, Ignacio struggled with securing his role in the mini-games, and stated that his partner played both roles and exited out of the mini-games without Ignacio's input. Ignacio stated that he wished players would share the roles and take turns picking the next game.

\subsubsection{Summary of Membership}

These results indicate that membership can be supported through careful design of an appropriately sized form factor and dedicated roles for each of the participants. The small form of the iPad prompted participants' close physical proximity, and having a role for both players encouraged participation. However, the lack of role enforcement and the small form factor sometimes worked against specific individual. The impact on game play of the lack of role enforcement indicates that designers should consider ways to enforce players' roles, potentially through player identification and explicit control mechanisms. Tradeoffs must be considered between the importance of teaching children to negotiate roles with one another dynamically and the structure of controlling those roles automatically. Likewise, a sufficiently large form factor would prevent individual children from taking too much controltheir arms would simply not reach — but would also mean less practice at sitting and acting appropriately when in close quarters as described above. 


\subsection{Partnership}

Partnership involves two people having specific responsibilities in achieving their mutual endeavor. Partnership differs from membership in that each person is dependent on the other's play, as it impacts the shared outcome. In this section, we describe first the serial behavior observed in Lego play and then how the cooperative gestures of serial, synchronized, and symmetrical actions all encouraged pairs to think and act like partners when playing with Zody.

\subsubsection{Collaborating through Turn-Taking Gestures}

Turn taking, a basic social skill, is frequently the target of intervention (e.g., Brok and Barakova 2010, Goodrich et al. 2011, Koegel and Koegel 1987, Mundy et al. 1986, Mundy et al. 1994, Scassellati et al. 2012, Schegloff 2000). Legos do not benefit from these gestures, and turn-taking in the Legos condition tended to involve one player issuing an order (one turn) and the other implementing it (another turn). In Zody, pairs took turns touching the arrows in the maze mini-game due to the assignment of two arrows per player and the need to travel in all four directions. Turns must be taken rapidly in this game-a slow playing pair will find their treasure "moved" by a capricious cat-which can challenge one's ability to wait for their partner to take a turn. For example, in dyad B, one partner regularly held the other's hand during the maze game, exerting a small amount of control even during the other player's turn.

As a more traditional-and slower moving-example, most dyads took turns choosing the next mini-game once one was completed. This behavior is not enforced, however, and so one player could dominate all choices, as seen in dyad C. These results indicate that games can facilitate turn taking behavior at multiple timescales. However, roles and design features in the technology or an outside human mediator are required to enforce the turn taking behaviors desired. An open question for designers then is how to facilitate these kinds of interactions without overly prescribing them.

\subsubsection{Coordinating trough Simultaneous Gestures}

"Simultaneous gestures" [Morris et al. 2006], which are cooperative gestures that occur at the same time, support partnership by enforcing coordination among members of a dyad. For example, in the Treasure Chase game, the players must synchronize their actions, because the game only accepts both fingerprints being pressed at once as appropriate input. To complete the synchronized finger-press gesture, students often spoke with one another, sometimes counting aloud to coordinate the time they would touch the screen "One-two-three-go!" In our observations, counting could occur out loud together or with one partner counting and the other listening. As pairs became more familiar with one another and with the game, explicit verbal interaction was often no longer necessary. A glance at each other, demonstrating eye contact (an important social skill in and of itself [Phillips et al. 1992]) or touching the partner on the arm, could convey the message that it is time to press the screen.

"Symmetrical actions" [Morris et al. 2006], (i.e., the same action by both players with each using their own controller), support partnership by setting up situations in which players help each other complete a mutual task through different roles. For example, Andrew described his partner as someone helping him with tasks: "Mhm, he helped me. Helped me find the pieces and helped me try to defeat, help me...He would help me try to throw these ice balls at the dragon." 
Cooperative gestures provide a level of coordinated engagement that extends a social interaction beyond a simple single turn taking activity. When each player can depend on the other to meet goals over the course of the mini-game and possibly all the games during the session, participants experience being needed by the other, and depending on the other, partnership.

In Zody, collaboration and coordination occurred without a mechanism for determining who was touching the interface (e.g., the Diamond Touch [Dietz and Leigh 2001]) or a human mediator to manage turn taking. Additional opportunities to practice partnership occurred each time a mini game ended and the pair needed to make a decision. Most pairs made decisions by engaging in a brief discussion during which they stated their preferences and reached consensus through compromise. For example, in the first Zody session for Dyad A, the pair used both verbal and nonverbal communication cues to determine what to do:

The teacher places the iPad in front of Tasha. Tasha says to Juan, "Don't touch it, she say don't touch it." The teacher says, "Okay guys, play together." Tasha says, "Okay" and releases the iPad. Juan pulls the iPad close to him to a point midway between them on the desk. He begins to scroll through comic-book style instructions. Leaning into the iPad space, Tasha says to him, "Let me read." Then they alternate touching the screen to advance the directions. Once at the end of the tutorial, Juan, with very brief glance at her says, "Okay (to) do this?" Tasha reads aloud the first word of the home screen script, says, "ready" and puts her thumb up. Juan says, "Okay, you walk this and get the vegetables." She points at him (see Figure 5) and says, "And you," as he continues saying, "And I get gophers." Then they begin to use the related controller button on their side of the screen.

- Field Notes from December 17, 2013

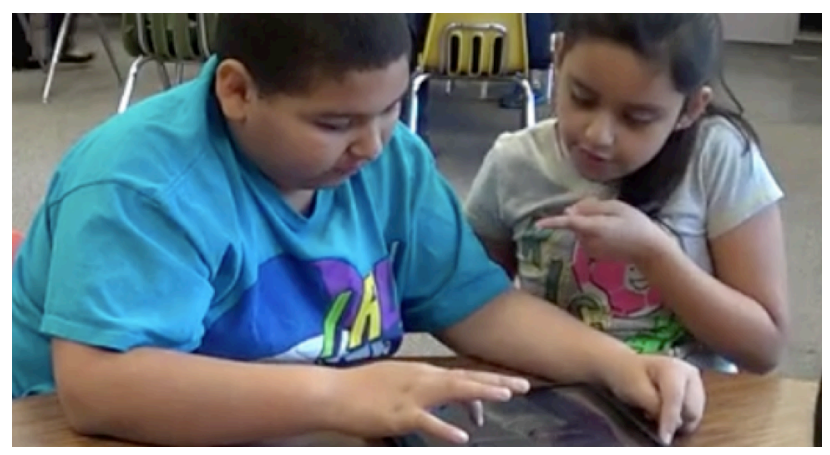

Figure 5: The pair negotiate roles in the gopher game by stating who will do which in-game task (throw fruit or run after gophers).

\subsubsection{Summary of Partnership}

Our results indicate that partnership can be supported by thoughtfully employing cooperative gestures of various dimensions. "Serial gestures" [Morris et al. 2006] provided the structure for pairs to take turns, supporting the use of "simultaneous gestures" [Morris et al. 2006] required of players to coordinate their actions in time. 

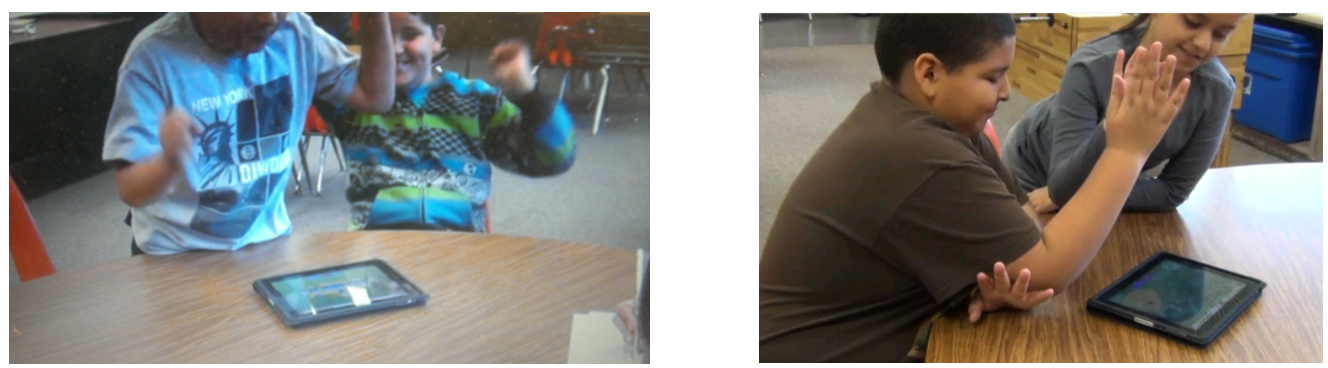

Figure 6: (left): Dyad B celebrates by smiling and making fist pumps. (right): A "win" creates the opportunity to celebrate together as they engage in a "high five" gesture.

Over time, each pair's coordination expanded beyond the cooperative gesture to include counting down together or looking at each other to be in sync. However, some pairs had difficulty coordinating their actions at the precise moment in time required to effectively play the game, leading to frustration when using cooperative gestures did not quickly result in finishing the task (e.g., finding the treasure in the dig game) and repeated cooperative gestures were required. Therefore, the potential for frustration created by cooperative gestures indicates that designers should consider the level of difficulty required by the pair to execute the coordinating movements, as it impacts their motivation to sustain play. The balance between the effort of working together and the challenge of an activity is an area for future research.

\subsection{Friendship}

Friendships are typically built on mutual interests, affinity for each other, and often involve having fun together, a developmental step in lasting relationships [Greenspan 2000]. Building friendships is a top priority in the development of early social engagement [Davis et al. 2014] as well as coping together and developing empathy for one another during less fun times.

\subsubsection{Experiencing Shared Joy through "Wins"}

The DIR/Floortime ${ }^{\mathrm{TM}}$ model, which inspired the creation of the Zody iPad game, argues for the importance of making therapeutic activities fun to motivate students to practice and learn social skills [Davis et al. 2014]. In particular, in this work, we found that rewards for winning a game can be powerful incentives for continued participation. Additionally, winning provides opportunities for shared joy, a foundational step towards friendship. In the Zody game, players receive visual and auditory praise, earn points, and "level up" after each mini-game is won. During our study, despite having been paired by random assignment with a classmate with whom they were not necessarily friends prior to the study, one or both partners typically made positive comments to each other in response to a victory. For example, players would regularly cheer for one another (e.g., "Yes we did it! Whoa!"), "high five," and demonstrate other expressions of shared joy with their wins (see Figure 6). Furthermore, during interviews, the students described forming friendships over the course of the study:

"It was fun actually. Usually um, usually me and Ignacio don't really get along, but since we started playing together, we actually started getting along, we started being friends." - Jesus 
These results indicate that the kind of acts of kindness and mutual celebration seen in the general population playing massively multiplayer online games [Nardi and Harris 2006] can be reproduced through smaller therapeutic games for children with ASD. These positive interactions can in turn create shared experiences from which a friendship can form beyond the session, thereby reinforcing social skills outside of structured treatments. Designers can leverage this momentum toward friendship formation by saving a pair's progress in the game, memorializing their interaction, and potentially reminding them of their play together. At the same time, by enabling small quick wins within a larger game structure, game play can serve to motivate and reinforce the therapeutic goals immediately.

\subsubsection{Demonstrating Empathy through "Losses"}

Empathy, a major part of friendship, is challenging for those with ASD [Baron-Cohen et al. 1988] but can be built and demonstrated by commiserating about an unfortunate event. The high frequency of opportunities to lose a round of play in most games in Zody allowed for ample opportunity to commiserate with one another. Specifically, the visual and auditory feedback provided by Zody supported expression of grief over joint losses, one's own loss, or that of a partner by encouraging players to make a commiserating statement such as "Almost got "em". This in-game script supported players in accepting the loss, commenting to their partner on the loss, and moving on with play. Furthermore, having some mini-games set up as parallel play (e.g., Dragon Blast) permitted participants' to observe their partner's play and comment on it thus making a connection to each other. Increasing the frequency of these high-emotional states is an important goal for technologies designed to teach and support social skills development because of the ease with which technology can provide fun experiences. The more practice with these emotional skills, the better the outcome for people learning social skills [Donnellan 1983].

These results indicate that games can support friendship by occasioning celebration and commiseration through the opportunity to observe the other's play and the use of wins and losses reinforced with visual and auditory feedback. When wins or losses occurred for one player, such as in Dragon Blast, or both, as in Gopher, pairs interacted by glancing at each other, commenting, or coordinating gestures such as giving a high five. In reference to the other player they might sigh or both spontaneously express their reaction by saying, "Oh no!" Thus, single and joint wins and losses were critical moments that provided an opportunity for the pairs to communicate their feelings about playing together. 


\begin{tabular}{|c|c|c|c|c|}
\hline Mini-game & Activity & $\begin{array}{l}\text { Cooperative } \\
\text { gestures }\end{array}$ & Social skill(s) & $\begin{array}{l}\text { Social } \\
\text { relationship(s) }\end{array}$ \\
\hline Maze & $\begin{array}{l}\text { Players work } \\
\text { together to move } \\
\text { character in four } \\
\text { directions }\end{array}$ & $\begin{array}{l}\text { Serial, } \\
\text { Asymmetric }\end{array}$ & Turn-taking & Membership \\
\hline $\begin{array}{l}\text { Treasure } \\
\text { Hunt }\end{array}$ & $\begin{array}{l}\text { Players push icons } \\
\text { simultaneously for } \\
\text { character to dig for } \\
\text { treasure }\end{array}$ & $\begin{array}{l}\text { Parallel, } \\
\text { Symmetric, } \\
\text { Additive }\end{array}$ & $\begin{array}{l}\text { Coordination, } \\
\text { Collaboration, } \\
\text { Compromise }\end{array}$ & Partnership \\
\hline $\begin{array}{l}\text { Dragon } \\
\text { Blast }\end{array}$ & $\begin{array}{l}\text { Player tosses } \\
\text { iceballs at the } \\
\text { dragon from } \\
\text { opposite sides }\end{array}$ & $\begin{array}{l}\text { Parallel, } \\
\text { Symmetric }\end{array}$ & Empathy & Friendship \\
\hline Gopher & $\begin{array}{l}\text { A player runs, } \\
\text { other rides on his } \\
\text { back and throws } \\
\text { fruit at gophers }\end{array}$ & $\begin{array}{l}\text { Parallel, } \\
\text { Asymmetric }\end{array}$ & $\begin{array}{l}\text { Joint Attention, } \\
\text { Communication, } \\
\text { Shared Joy }\end{array}$ & $\begin{array}{l}\text { Membership, } \\
\text { Partnership, } \\
\text { Friendship }\end{array}$ \\
\hline
\end{tabular}

Table 3: Sample of Zody mini-game activities with cooperative gestures aligned with related social skill(s) and social relationship(s).

\subsection{A summary of the cooperative gestures}

Zody presented a variety of ways for pairs to perform collaborative actions. Unlike the dominant pattern in the Lego set play, that in this brief study, mostly promoted a serial, asymmetric pattern of interaction, Zody offered variety of combinations. Table 3 describes four of the mini games, presents examples of in-game activities, and identifies the related cooperative gesture, the social skill that it supported, and the type of social relationships that it engendered.

\section{DISCUSSION AND CONCLUSION}

The majority of research on social skills interventions for individuals with ASD focuses on the development of specific social skills, (such as initiating greetings, turntaking, making eye contact, smiling, or waving goodbye [Ozonoff 2002, Krasny 2003, Wilczynski 2007]) or one type of social relationship (such as social inclusion/ membership [Kalyva and Avramidis 2005]). However, in examining the impact of a collaborative iPad game on social skills, we found that one technology can support multiple skills and relationships. Designers can support development and engagement in a variety of social relationships by using joining in features to support membership, coordinating actions to support partnership, and commenting on the shared experience to support friendship.

These distinct social events can be designed to occur within a single play session. The ability to incorporate these multiple interaction styles can also help maintain engagement and attention to the game or therapy [Ringland et al. 2014]. Overall, designers must balance the therapeutic benefit of certain interactions with the fun of others. Games have great potential as an intervention, due to the ability to 
interweave thoughtfully applied design elements with the naturally occurring contingencies (i.e., having fun together).

These insights leave us with the following questions: would more intimate prosocial behaviors, such as collaborating and sharing wins and losses, lead to sustained outcomes beyond game play? What role do other game elements have in supporting pro-social behaviors in a maintainable way? How can technology intermingle social skill interventions within video games to achieve the greatest impact? Indeed, it may be impossible to truly tease apart all the active components when considering a holistic gaming experience. Nonetheless, further examination is warranted, because children with ASD who play video games have been reported to spend roughly twice as much time playing as typically-developing peers who also play video games [Mazurek et al. 2011]. In summary, collaborative games on tablets provide an effective and efficient platform for sustainable social skills intervention in that they are portable, low cost, fun, require no human mediator. Moreover, the framework of three types of social relationships-membership, partnership, and friendship-can inform the design of new social skill interventions for children with ASD.

\section{ACKNOWLEDGMENTS}

We thank all of the students, parents, teachers, paraprofessionals who participated in this study, specifically Sara Cabel, Wendy Miller, Teri Louer. We also thank Kelly McKinnon and Dr. Joe Donnelly at the Center for Autism and Neurodevelopmental Disorders. This research was approved by human subjects protocol 2013-9842 through UC Irvine and funded by a generous gift from Robert A. and Barbara L. Kleist. The Zody game was provided free of charge by SymPlay, and we thank Bill Fisher, Bruce Brownstein, and Josh Feder for their insight into the game and to support our research. We thank Jed Brubaker, Lynn Dombrowski, Sen Hirano, and members of the STAR research group at UC Irvine for their valuable input on drafts of this paper.

\section{REFERENCES}

Roger Bakeman and John. R. Brownlee, J. R. 1980. The strategic use of parallel play: A sequential analysis. Child Development, 873-878.

Simon Baron-Cohen. 1988. Social and pragmatic deficits in autism: Cognitive or affective? Journal of autism and developmental disorders, 18(3), 379-402

Scott Bellini and Andrea Hopf. 2007. The Development of the Autism Social Skills Profile A Preliminary Analysis of Psychometric Properties. Focus on Autism and Other Developmental Disabilities, 22(2), 8087.

John Bowers, James Pycock, and Jon O'brien. 1996. Talk and embodiment in collaborative virtual environments. In Proceedings of the SIGCHI Conference on Human Factors in Computing Systems,5865. ACM.

LouAnne E. Boyd and Deborah M. Ward. 2013. Ward. Social Compass Curriculum Three Descriptive Case Studies of Social Skills Outcomes for Students With ASD. SAGE Open 3, no. 4: 2158244013507289.

Jeroen C.J. Brok and Emilia I. Barakova. 2010. Engaging autistic children in imitation and turn-taking games with multiagent system of interactive lighting blocks. In Entertainment Computing-ICEC 2010, 115-126. Springer Berlin Heidelberg.

Kathy Charmaz and Liska Belgrave. 2002. Qualitative interviewing and grounded theory analysis. The SAGE handbook of interview research: The complexity of the craft, 2. 
Yufang Cheng and Jun Ye. 2010. Exploring the social competence of students with autism spectrum conditions in a collaborative virtual learning environment--The pilot study. Computers and Education, 54(4), 1068-1077.

Scott A. Cunningham, Benjamin Engelstätter, and Michael R. Ward. 2011. Understanding the effects of violent video games on violent crime. No. 11-042. ZEW Discussion Papers.

Andrea Davis, Lahela Isaacson, and Michelle Harwell. 2014. Floortime Strategies to promote development in children and teens: A user's guide to the DIR model.

Geraldine Dawson, Karen Toth, Robert Abbott, Julie Osterling, Jeff Munson, Anette Estes, and Jane Liaw. 2004. Early social attention impairments in autism: social orienting, joint attention, and attention to distress. Developmental psychology, 40(2), 271.

Dennis J. Delprato. 2001. Comparisons of discrete-trial and normalized behavioral language intervention for young children with autism. Journal of autism and developmental disorders, 31(3), 315-325.

Paul Dietz and Darren Leigh. 2001. DiamondTouch: a multi-user touch technology. In Proceedings of the 14th annual ACM symposium on User interface software and technology, 219-226. ACM.

Anne M. Donnellan. 1983. An Educational Perspective of Autism: Implications for Curriculum Development and Personnel Development.

DSM-IV-TR: Diagnostic and statistical manual of mental disorders, text revision. American Psychiatric Association, 2000.

The Harris Poll 10-Video Games_2 27 13. (2013). Majority of Americans see connection between video games and violence in teens. Retrieved Oct 2 from http://www.harrisinteractive.com/vault/Harris\%20Poll\%2010\%20\%20Video\%20Games_2\%2027\%2013.

Eynat Gal, Nirit Bauminger, Dina Goren-Bar, Fabio Pianesi, Olivero Stock, Massimo Zancanaro, and Patrice L. T. Weiss. 2009. Enhancing social communication of children with high-functioning autism through a co-located interface. AI and Society, 24(1), 75-84.

Mohammad Ghaziuddin, Neera Ghaziuddin, and John Greden. 2002. Depression in persons with Autism: Implications for research and clinical care. Journal of autism and developmental disorders 32, no. 4 299-306.

Leonardo Giusti, Massimo Zancanaro, Eynat Gal, and Patrice L. T. Weiss. 2011. Dimensions of collaboration on a tabletop interface for children with autism spectrum disorder. In Proceedings of the SIGCHI Conference on Human Factors in Computing Systems, 323304.

Stanley I. Greenspan and Nancy Lewis. 2000. Building healthy minds: The six experiences that create intelligence and emotional growth in babies and young children. Da Capo Press.

Peter F. Gerhardt and Erik Mayville. 2010. Assessment of social skills and social competence in learners with autism spectrum disorders. In Practitioner's Guide to Empirically Based Measures of Social Skills,193-205. Springer New York.

Michael A. Goodrich, Mark A., Colton, Bonnie Brinton, and Martin Fujiki. 2011, March. A case for lowdose robotics in autism therapy. In Proceedings of the 6th international conference on Human-robot interaction, 143-144. ACM.

Steven E. Gutstein and Rachelle K. Sheely. 2002. Relationship development intervention with young children: Social and emotional development activities for Asperger syndrome, Autism, PDD, and NDL (Vol. 2). Jessica Kingsley Publishers. 


\section{Collaborative iPad Game L. Boyd et al. 39:19}

Alexis Hiniker, Joy W. Daniels, and Hedi Williamson. 2013. Go go games: Therapeutic video games for children with autism spectrum disorders. Proceedings of the 12th International Conference on Interaction Design and Children, 463-466.

Linda Hughes. 1983. Beyond the Rules of the Game, Why Are Rooie Rules Nice? In Manning, F. ed. World of Play. In Proceedings of 7th Annual Meeting of the Association of the Anthropological Study of Play, Factors in Computing Systems 1633-1642. ACM.

Richard Hurtig and Debora Downey. 2009. Augmentative and alternative communication in acute and critical care settings. Plural Pub.

Juan Pablo Hourcade, Natasha E. Bullock-Rest, and Thomas E. Hansen. 2012. Multitouch tablet applications and activities to enhance the social skills of children with autism spectrum disorders. Personal and ubiquitous computing, 16(2), 157-168.

Juan Pablo Hourcade, Stacy R. Williams, Ellen A. Miller, Kelsey E. Huebner, and L. J. Liang. 2013. Evaluation of tablet apps to encourage social interaction in children with autism spectrum disorders. In Proceedings of the SIGCHI Conference on Human Factors in Computing Systems, 3197-3206. ACM.

Efrosini Kalyva and Elias Avramidis. 2005. Improving Communication Between Children with Autism and Their Peers Through the 'Circle of Friends': A Smallscale Intervention Study. Journal of applied research in intellectual disabilities, 18(3), 253-261.

Connie Kasari, Brandt Chamberlain, and Nirit Bauminger, N. 2001. Social emotions and social relationships: can children with autism compensate?

Alan E. Kazdin. 2011. Single-case research designs: Methods for clinical and applied se. Oxford University Press

Julie A. Kientz, Matthew S. Goodwin, Gillian. R. Hayes, and Gregory D. Abowd. 2013. Interactive Technologies for Autism. Synthesis Lectures on Assistive, Rehabilitative, and Health-Preserving Technologies 2, no. 2: 1-177.

Robert L. Koegel, Mary C. O'dell, and Lynn K. Koegel. 1987. A natural language teaching paradigm for nonverbal autistic children. Journal of autism and developmental disorders, 17(2), 187-200

Lori Krasny, Brenda J. Williams, Sheeri Provencal, and Sally Ozonoff. 2003. Social skills interventions for the autism spectrum: Essential ingredients and a model curriculum. Child and adolescent psychiatric clinics of North America, 12(1), 107-122.

Daniel B. LeGoff, D. B. 2004. Use of LEGO@ as a therapeutic medium for improving social competence. Journal of Autism and Developmental Disorders, 34(5), 557-571.

Daniel. B. Legoff \& Michael Sherman. 2006. Long-term outcome of social skills intervention based on interactive LEGOC play. Autism, 10(4), 317-329.

Ovsanna. T. Leyfer, Susan E. Folstein, Susan Bacalman, Naomi O. Davis, Elena Dinh, E., Jubel Morgan, Helen Tager-Flusberg and Janet E. Lainhart. 2006. Comorbid psychiatric disorders in children with autism: interview development and rates of disorders. Journal of autism and developmental disorders, $36(7), 849-861$

Rebeeca. W. Lieb. 2011. A Developmental Model Predicting Adjustment in Youth with Autism Spectrum Disorders: The Role of Executive Functions, Social Impairment, and Friendship Quality. Dissertations. Paper 92. http://ecommons.luc_diss/92 
Micah O. Mazurek, Paul T. Shattuck, Mary Wagner, and Benjamin P. Cooper. 2011. Prevalence and correlates of screen- based media use among youths with autism spectrum disor- ders," J Autism Dev Disord, pp. 1-11.

Kathleen F. McCoy and Annalu Walker. 2009. Introduction to the Special Issue on AAC. ACM Transactions on Accessible Computing (TACESS) 1, no. 3.13.

Joanna McGrenere. 1996. Design: Educational Multi-Player Games A Literature Review.

Meredith R. Morris, Anqi Huang, Andreas Paepcke, and Terry Winograd. 2006. Cooperative gestures: multi-user gestural interactions for co-located groupware. In Proceedings of the SIGCHI conference on Human Factors in computing systems,1201-1210. ACM.

Peter Mundy, Merian Sigman, and Connie Kasari. 1994. Joint attention, developmental level, and symptom presentation in autism. Development and Psychopathology,6(03), 389-401.

Peter Mundy, Marian Sigman, Judy Ungerer, and Tracy Sherman. 1986. Defining the social deficits of autism: The contribution of nonverbal communication measures. Journal of child psychology and psychiatry, 27(5), 657-669.

Bonnie Nardi, and Justin Harris. 2006. Strangers and friends: Collaborative play in World of Warcraft. In Proceedings of the 2006 20th anniversary conference on Computer supported cooperative work, 149-158. ACM.

Gael I. Orsmond, Marty W. Krauss, and Marsha M. Seltzer. 2004. Peer relationships and social and recreational activities among adolescents and adults with autism. Journal of autism and developmental disorders, 34(3), 245-256.

Sally Ozonoff. 2002, Presentation at the TEACCH conference, Atlanta.

Wendy Phillips, Simon Baron-Cohen, and Michael Rutter. 1992. The role of eye contact in goal detection: Evidence from normal infants and children with autism or mental handicap. Development and Psychopathology, 4(03), 375-383.

Anne Marie Piper, Ellen O'brien, Meredith R. Morris, and Terry Winograd. 2006. SIDES: a cooperative tabletop computer game for social skills development. In Proceedings of the 2006 20th anniversary conference on Computer supported cooperative work,1-10. ACM.

Lisa L. Travis and Marian Sigman. 1998. Social deficits and interpersonal relationships in autism. Mental Retardation and Developmental Disabilities Research Reviews, 4(2), 65-72.

Brian Reichow and Fred R. Volkmar. 2010. Social skills interventions for individuals with autism: Evaluation for evidence-based practices within a best evidence synthesis framework. Journal of autism and developmental disorders, 40(2), 149-166.

Kathryn E. Ringland, Rodrigo Zalapa, Megan Neal, Lizbeth Escobedo, Monioca E. Tentori, and Gillian R. Hayes. 2014. SensoryPaint: a natural user interface supporting sensory integration in children with neurodevelopmental disorders. In CHI'14 Extended Abstracts on Human Factors in Computing Systems (pp. 1681-1686). ACM.

Brian Scassellati, Henny Admoni, and Maja Mataric. 2012. Robots for use in autism research. Annual Review of Biomedical Engineering, 14, 275-294

Emanual A. Schegloff. 2000. Overlapping talk and the organization of turn-taking for conversation. Language in society, 29(01), 1-63.

Andrew Sears and Vicki L. Hanson, 2012.Representing Users in Accessibility Research. ACM Transactions on Accessible Computing (TACCESS) 4, no. 2: 7. 
A. Fleming Seay, William J. Jerome, Kevin S. Lee, and Robert E. Kraut. 2003. Project Massive 1.0: Organizational Commitment, Sociability and Extraversion in Massively Multiplayer Online Games. In DIGRA Conf..

Andrea Tartaro and Justine Cassell. 2011. Authorable virtual peers: technology as an intervention for difficulties with peer social interaction in autism spectrum and related disorders. (Doctoral Dissertation)

Josh Wainer. 2012. Facilitating collaboration among children with autism through robot-assisted play (Doctoral dissertation, University of Hertfordshire).

Viktor Wendel, Michael Gutjahr, Stefen Göbel, and Ralf Steinmetz. 2013. Designing collaborative multiplayer serious games. Education and Information Technologies, 18(2), 287-308.

Susan M. Wilczynski, Kathryn Menousek, Melissa Hunter, and Dipti Mudgal. 2007. Individualized education programs for youth with autism spectrum disorders. Psychology in the Schools 44, no. 7, 653666.

Susan W. White, Kathleen Keonig, and Lawerance Scahill. 2007. Social skills development in children with autism spectrum disorders: A review of the intervention research. Journal of autism and developmental disorders 37, no. 10 1858-1868

Yan Xu, Xiang Cao, Abigail Sellen, Ralf Herbrich, and Thore Graepel. 2011. Sociable killers: understanding social relationships in an online first-person shooter game. In Proceedings of the ACM 2011 conference on Computer supported cooperative work, 197-206.

Statement of Contribution:

This paper contributes to the discussion around collaborative gestures for children with ASD by evaluating the impact of an iPad game designed to support social skills. Additionally, the context of this work raises particular concerns for sustainability as previous works are not easily translated into everyday practice beyond a research setting due to portability, cost, and need for a mediator. Findings suggest a process through which to developers can support social relationships through collaboration. The results of the pilot deployment with school-aged children with ASD have not been published elsewhere and make possible an empirical validation of design guidelines produced in earlier work. 